\title{
Restructuring and Formalizing: Scholarly Communication as a Sustainable Growth Opportunity in Information Agencies?
}

\author{
A. J. Million \\ University of Michigan, USA. millioaj@umich.edu \\ Cynthia Hudson-Vitale \\ Penn State University, USA. cynhudson@gmail.com
}

Heather Moulaison Sandy

University of Missouri, USA. moulaisonhe@missouri.edu

\begin{abstract}
Emerging technologies are revolutionizing the field of scholarly communication. Because of this, scholars increasingly need specialized support during all stages of the research process. With the academic library as the unit of analysis, two concepts from Rogers' Diffusion of Innovation theory and organizational innovation literature are drawn upon to assess the sustainability of scholarly communication work in libraries. These concepts are organizational restructuring and formalization. Data on Association of Research Libraries (ARL) employees with relevant job titles and three digital curation competencies documents are analysed. Study findings suggest that ARL information agencies have restructured to provide added research support and that skills associated with scholarly communication positions are becoming more uniform. We conclude that scholarly communication information professionals are part of a sustainable area of practice within ARL information agencies, that has matured over the past decade, and this trend is likely to continue in at least the short term.
\end{abstract}

\section{KEYWORDS}

Information professionals; Scholarly communication; Digital curation; Information agencies; Sustainability (management); Diffusion of innovations

\section{INTRODUCTION}

The emergence of new technologies to support publishing and communication (including social networks and online reference management and sharing platforms) have fundamentally changed the way that scholars work (Regazzi, 2015) and have altered the research process in which they engage. Scholarly communication has become more complex as a result of new and emerging technologies. Scholarly communication, an area supported by information professionals, is defined as:

the study of how scholars in any field (e.g., physical, biological, social and behavioural sciences, humanities and technology) use and disseminate information through formal and informal channels. The study of scholarly communication includes the growth of scholarly information, the relationships among research areas and disciplines, the information needs and uses of individual user groups, and the relationships among formal and informal methods of communication (Borgman, 1990, pp. 13-4).

Scholarly communication enables the work of researchers at universities and organizations that are dedicated to creating new knowledge. In the United States (U.S.), over half of all federal research dollars are granted to university-affiliated researchers (Regazzi, 2015) making universities a hub for the creation of new knowledge.

\section{Supporting Scholars}

Supporting scholarly communication on university campuses in an age of emerging technologies has naturally fallen to information professionals based in information agencies, such as academic libraries. Traditionally, academic libraries have divided the expertise they provide into technical services and public services, but given the complexity of technologies combined with the increasingly sophisticated needs of users, a new breed of information professional must emerge (e.g., Kowalski, 2017). In the case of scholarly communication questions, not only must the information professional curate and supply access to scholarship, but he/she must also work with scholars to organize, provide access to, save, and share their work. Providing specialized support to scholars (e.g., Ketchum, 2017) during the research process has quickly become the purview of the academic library.

As the needs of researchers and scholars have changed, the work of information professionals has evolved in parallel. Working to support the field of "scholarly communication today reflects a [need to master an ever-growing] constellation of tools, practices, and competencies" (Cross, Oleen, \& Perry, 2017, p. 365). The support scholarly communication information professionals provide to researchers varies according to the priorities of the institutions in which they work, the areas of expertise of the scholars whom they support, and their own skills and training. For the purposes of this paper, we consider work that supports 
scholarly communication as: assistance with digital curation, research data management, and open access and publishing. Although the competencies and skills to support this work have been codified in several documents (some of which are analyzed in this paper), little is known about the sustainability of scholarly communication work in information agencies.

This paper assesses the role of the scholarly communication information professional in an attempt to understand the sustainability of this non-traditional work. To assess sustainability, we review literature that pertains to the evolving roles and missions of academic libraries and the role that information professionals can play in supporting scholarly communication at their institutions. Next, we present the concepts of restructuring and formalization from Rogers' (2003) Diffusion of Innovations (DOI) Theory and organizational innovation literature, under the assumption that scholarly communication positions have diffused among information agencies in recent years. ${ }^{1}$ Informed by concepts from DOI, we discuss findings from an analysis of Association of Research Libraries (ARL) job statistics and a qualitative evaluation of three scholarly communication competency documents specific to digital curators. Based on our findings, we conclude that ARL libraries have restructured to add scholarly communication positions due to the value these information professionals bring, and the alignment of competency documents suggests that the work of information professionals is becoming more uniform. DOI predicts that restructuring and formalization in organizations are associated with slower rates of change. Thus, evidence suggests it is likely that scholarly communication information professionals will remain a sustainable addition to ARL information agencies in the short term. We conclude by discussing limitations to our analysis and offer directions for future research.

\section{Sustainability}

For the purposes of this paper, we define sustainability as the stability of defined roles and responsibilities within information agencies. The United Nations Brundtland Report (1987) provides another definition, which says that sustainability is "development that meets the needs of the present without compromising the ability of future generations to meet their own needs" (p. 37). Applied to work in information agencies, this definition implies that sustainability occurs when individuals carry out work that does not compromise the ability of their successors to do the same. We do not discount the value of this definition; however, it is inappropriate for use in this paper. The reason we adopt the first definition is we are ultimately concerned with the perpetuation of scholarly communication as a set of positions and practices in ARL information agencies. Thus, we are not concerned with the question of whether short-term practices by scholarly communication professionals are likely to be harmful or counterproductive in the long-run.

\section{Research Questions and Rationale}

Based on survey data from 2012, the Council of Prairie and Pacific University Libraries (COPPUL) Scholarly Communications Working Group found the field of scholarly communication was not yet coalescing to form a community of practice in libraries (Swanepoel, 2015). However, after ten years of the Association of College and Research Library (ACRL) Scholarly Communication Roadshow, Cross, Oleen, and Perry (2017) found the field has significantly matured.

Given the work these information professionals carry out, and given the support that researchers and scholars require thanks to changing technologies, this paper addresses two research questions:

RQ1. Going forward, how sustainable is the work of scholarly communication information professionals in ARL information agencies likely to be?

RQ2. To what extent has a sub-area of scholarly communication practice (i.e., digital curation) emerged as a cohesive area of practice?

The first research question (RQ1) addresses the primary issue examined in this study. Research question two (RQ2) pertains to a sub-area of scholarly communications practice that must be examined to answer RQ1.

\section{LITERATURE REVIEW}

Scholarly communication is a field that has needed to adapt to modern technology, research approaches, and communication methods. Information professionals supporting scholarly communication have emerged to assist researchers in navigating this new landscape. As Brantley, Bruns, and Duffin, (2017) explain, "The activities of scholarly communication-support librarians have grown and changed in recent years due to the increasingly complex nature of modern digital scholarship" (p. 137). For example, Regazzi (2015) identifies big data and big science as two changes that have profoundly affected researchers and the work they do. Hey, Tansley, and Tolle's (2009) canonical text also correctly identifies a marked shift towards computational

\footnotetext{
${ }^{1}$ This assumption is based on Cross, Oleen, and Perry's (2017) history of the ACRL Scholarly Communications Roadshow and prior efforts to educate librarians about the need to engage in scholarly communication work.
} 
and data intensive research in the academic environment. Furthermore, the 2013 U.S. Office of Science and Technology Policy memorandum, "Expanding Public Access to the Results of Federally Funded Research" hastened the development of library services that support the open access and sharing of research outputs. Scholarly communication information professionals have learned to navigate the increasingly complex field of scholarly communication and its related technologies, and work to support scholars in their use of these technologies through services they offer. Borgman (2000) clarifies that, in terms of the intersection of digital libraries and scholarly communication, information professionals are more interested in the services digital libraries can provide (Borgman, 2000, p. 415); in this way, they might be said to resemble both the technical services librarians and the public services librarians of the past.

\section{The Evolving Academic Library}

In response to the changing needs of their users and in support of the new services they must now provide, academic libraries have changed dramatically, beyond moving from a front-of-the-house/back-of-the-house binary model to convergence among the two (Bossaller \& Moulaison Sandy, 2017; Kowalski, 2017). Library reorganization has been a key way in which academic libraries have positioned themselves for the future of access. In examining the literature, Novak and Day (2015) identify five steps libraries typically undertake during the reorganization process: libraries 1) identify drivers for change, 2) carry out analysis and diagnosis, 3) communicate the change plan, 4) implement the change, and 5) carry out continuous assessment afterward. Assigning new tasks to staff based on the analysis and diagnosis step takes place during the implementing the change step. It is at this point that staff are trained with any new skills they might need and are ideally placed in new positions based on their existing skills, talents, and proclivities. Staff may, therefore, have been hired under one set of requirements or professional expectations, and find themselves taking on new work in other areas.

\section{Information Professionals Supporting Scholarly Communication}

New job titles and requirements have emerged in support of the changing academic library and changing academic research practices. Positions may no longer require information professionals to have ALA-accredited degrees in Library and Information Science (LIS) (T. Dawes, personal communication, 2016). Research by Fearon et. al. (2013) found that the librarians supporting research data management services include subject expertise across varied research disciplines, in addition to, or in replacement of, the traditional LIS degree. These information professionals, therefore, have the potential to come from a variety of backgrounds and may have traditional LIS degrees, other areas of specialization, or both.

Anecdotally, there has been a marked increase in scholarly communication information professionals in academic libraries, but little is known about them other than the gender of SCHOLCOMM listserv members (Hayes \& Kelly, 2017). According to the literature, in terms of their work, information professionals in this domain are responsible for a number of sub-activities. They may be expected to assist faculty and other users with the scholarly communication process (Klain-Gabbay \& Shohamb, 2016). Promoting the open access movement among library users is also seen as a scholarly communication problem (Potvin, 2013; Rodriguez, 2015).

One primary sub-area of scholarly communication is digital curation, and by extension, research data management. To support scholars throughout the research process, scholarly communication information professionals must also assist with the curation and use of data and digital assets in light of the technological advances mentioned earlier (Fearon et al., 2013). Indeed, open access and open research services are inherent in the developing of support for research data management and curation. Fearon and his co-authors find that $85 \%$ of institutions who archive data do so to support open access (p. 56). Further, one of the core library services for research data management involves consultations and education around public access to all research outputs, not just data, but also code, analyses, protocols, workflows, publications, and more.

Information professionals working in this area also attempt to understand their users' information needs and digital information preferences (Maron \& Smith, 2009). Lewis, Sarli, and Suiter (2015) found that many institutions are developing services to support researchers in managing their scholarly identities and track research outputs. To support this service, information professionals developed skills in data analysis, digital humanities, data management, and an understanding of various metric types. In short, as the field has evolved, scholarly communication information professionals have moved from advocating for open scholarship to actively providing services that relate to the communication and publishing of research, research data, and additional aspects of scientific inquiry.

\section{DIFFUSION OF INNOVATIONS}

It is challenging to predict the future, but Rogers' (2003) Diffusion of Innovations (DOI) theory and organizational innovation literature provides concepts to examine the sustainability of scholarly communication work in ARL information agencies. No theory can predict the future; however, DOI is one of the most cited works in social scientific literature (Green, 2016). Below, we introduce DOI and describe how the theory helps predict change in information agencies like libraries with a focus on the 
concepts of organizational restructuring and formalization. In social scientific literature, DOI is used to explain how and why innovations spread. An innovation is defined as "any idea, practice, or project that is perceived as new by an individual or other unit of adoption" (Rogers, 2003; pp. 11-12). In this paper, we define an innovation as scholarly communication positions within ARL libraries. Stemming from the work of rural sociologists (Ryan \& Gross, 1943), Rogers (1962) is credited with popularizing DOI by synthesizing 508 studies that explained why individuals and organizations adopt innovations (Valente \& Rogers, 1995). In doing so, Rogers (2003) identified four causal factors: an innovation, communication, time, and a social system (p. 11). We focus on innovations (i.e., scholarly communication positions) and social systems (i.e., ARL libraries) below.

\section{Innovation in Organizations}

Organizations are "organized bod[ies] of people with a particular purpose," and they tend to be complex (Oxford, n.d., para. 1). Originally, DOI emerged as a theory that focused on the decisions of individuals. Later developments extended it to describe innovation in organizations, such as academic libraries, through the use of metaphors. For example, one metaphor is that of an organizational decision-making process. Another metaphor is that of organizational structure.

Regarding the metaphor of organizational decision-making, one way that Rogers extended DOI was through the creation of a six-part model. Elaborating, Rogers (2003) argued that organizations act as if they possess agency and try to reduce uncertainty about the costs and benefits of adopting and/or rejecting innovations. The six stages of organizational innovation-decisions are: agenda-setting, matching, redefining, restructuring, clarifying, and routinizing (p. 421). Agenda-setting refers to where goals and agendas are set by leaders. Matching describes staff searching for and finding solutions to meet agendas. Redefining and restructuring mean that after the matching stage ends, agendas are refined and innovations adopted. Finally, clarifying describes the process of generating buy-in from staff (p. 427) and routinizing is when staff no longer perceive an innovation as new (p. 429). We do not focus on decisions to create scholarly communication positions in this paper, but Rogers' offers a way to infer changes in information agencies that have already taken place through a process of diffusion. Demonstrated by the creation of scholarly communication positions, we argue this change pertains to library restructuring.

Another metaphor central to this paper is the concept of organizational structure. Pugh (1990) says that organizational structures are "regularities in activities such as task allocation, coordination, and supervision" (p. 1), and Rogers (2003) argues there are six traits that determine if organizations will change. Rooted in organizational innovation literature, these structural traits are: centralization, formalization, complexity, interconnectedness, organizational slack, and size. Formalization describes the extent to which "an organization emphasizes its members' following rules and procedures" (p. 411) and we interpret it as information agencies creating positions that align with professionally uniform practices.

Literature examining innovation in organizations from a structural view supports Rogers' arguments - especially when it comes to the matter of formalization. Formalized job roles are associated with slower rates of innovation. For example, in a study of social welfare organizations Hague and Aiken (1967) found that a low degree of job codification is associated with a high rate of change. In 1981, Howard looked at four university libraries and found that the rate of innovation is negative for centralized, formal, and stratified organizations. More recently, Chen and Chang (2012) looked at 260 organizations via survey and determined that a high degree of organizational formalization slows decision speeds and organizational innovation. Formalization is not the only predictor of change in organizations, but it does align with the restructuring phase of Rogers' (2003) innovation decision-making process.

\section{METHODOLOGY}

\section{Assessing the Prevalence of Scholarly Communication Positions in ARL Libraries}

To understand the growth of the number of scholarly communication information professionals employed in large academic libraries in North America, we analyzed data for positions coded in the ARL Salary Survey. Although ARL institutions are not representative of all information agencies supporting research, they include some of the largest and most prestigious academic libraries in the U.S. and Canada. Once per year, 125 ARL libraries submit employee data for all positions. Survey coordinators choose one job code to apply per staff member, and later this data is cleaned, normalized, and aggregated.

For the current study, we examined data for positions coded as Scholarly Communication Librarian (SCHOLAR) and Digital Curation Librarian (DIGICUR). The SCHOLAR code is defined in the salary survey as a library staff member who is involved in scholarly communication. These individuals work with or promote open publication access, provide advice regarding copyright issues, and more. The DIGICUR code is defined as a library staff member who creates and curates digital collections in the sciences, social sciences, or humanities, or who works with data-management issues across multiple disciplines. As noted earlier, digital curation is a sub-area of scholarly communication. Both of these positions were analyzed given their support for the communication and publishing of scholarship. The year 2012 marked the first time ARL collected data regarding these two categories. 


\section{Skills and Competencies Assessment}

Researchers also analyzed the recommended skills and competencies required for digital curation and data management, an area of expertise that blends back-of-the-house technology expertise with front-of-the-house service provision in support of the scholarly communication process. The project team applied a multi-step approach: (1) identification of relevant guidelines; (2) compilation of competencies/skills as a way to enable uniform mark-up during coding; (3) the inductive development of broad categories; and, (4) the coding of each competency to a category.

To find as many relevant digital curation skills and recommendation reports or research, the following approach was applied:

3. Databases searched: Library Literature \& Information Science; Library, Information Science \& Technology Abstracts; Google Scholar; Google

4. Keywords used: "digital curation skills"; "digital curation curriculum"; "digital curation training"

This search returned 418 articles. Given that we sought to understand competencies and skills for digital curation and research data management - a specific subset of work carried out by scholarly communication information professionals — documents focusing on practice rather than theory were retained. Articles analyzing position announcements were deemed unreliable since there was no way to know how successful searches would be or how closely the incumbent would meet requirements and would carry out the work as described. With this in mind, we developed and applied the following inclusion criteria to narrow search results:

1. Published 2007-present;

2. Written in English;

3. Specifically indicated necessary or recommended competencies/skills for properly curating or stewarding data; and

4. Competencies/skills were not developed by analysing job advertisements or reviewing the literature.

The following three competency documents were analyzed: Librarians' Competencies Profile for Research Data Management (2016), Matrix of Digital Curation Knowledge and Competencies (2009), and Preparing the Workforce for Digital Curation (2015). Below, we present each in chronological order based on their publication dates.

The Matrix of Digital Curation Knowledge and Competencies published in 2009 is one of the earliest documents that articulated the requisite skills for digital curation work. These skills were developed as part of the DigCCurr project led by Helen Tibbo and Cal Lee at the University of North Carolina as part of an Institute of Museum and Library Services (IMLS) project. This IMLS-funded project developed library school curricula and held a number of training events to support the diffusion of digital curation activities. A project matrix comprised of six dimensions was developed as a method to identify and organize material to be covered in digital curation curricula. These dimensions are: (1) mandates, values, and principles; (2) functions and skills; (3) professional, disciplinary, institutional, organizational, or cultural context; (4) type of resource; (5) prerequisite knowledge; and (6) transition point in information continuum. The dimension "function and skills" was the source for this research, because it is defined as "know how," as opposed to conceptual, attitudinal, or declarative knowledge.

In 2015, the National Research Council of the U.S. National Academies of Science released the report Preparing the Workforce for Digital Curation. This report was authored by a committee on "Future Career Opportunities and Educational Requirements for Digital Curation" and was intended to examine workforce-related issues in information agencies with an eye toward future economic development. The committee was composed of experts and industry representatives in library and information science, labor economics, and domain-specific scientific fields. More recently, the Librarians' Competencies Profile for Research Data Management, was published in 2016 by the Joint Task Force for Librarians' Competencies in Support of E-Research and Scholarly Communication convened by the ARL. The aim of this task force was to outline the competencies needed for eresearch, repository management, and scholarly communication. The task force consisted of representatives from ARL institutions, the Canadian Association of Research Libraries, the Confederation of Open Access Repositories, and the Association of European Research Libraries.

\section{Compilation of Competencies}

The three competency guidelines varied in length and detail; two were documents, and one was a matrix of skills. Formats also varied, with one being an HTML document and two being in PDF format. To normalize these documents, a PDF was made of the HTML document. Next, using Adobe Acrobat Pro, we documented codes by highlighting relevant text and inserting comments for each competency. The level of detail for each competency document varied. The Matrix of Digital Curation Knowledge and Competencies included function categories, such as "access" and "administration" and sub-level functions, such as the "generation of dissemination information package," which went into great detail about each overarching category. To ensure comparison across the competency documents was reliable, we used high-level descriptions and text in the definition and explanation section of each document to conduct the qualitative coding process. 
Content analysis is an appropriate methodology for understanding and reducing information from existing data sources such as competency documents. Because no taxonomy of qualitative competency guidelines for digital curation exists, we employed an inductive structural coding approach, which involved identifying concepts and skills that may apply to large segments of text and enabled the comparison of frequency counts across cases (Saldaña, 2013). Inductive coding means that coded skills reflect the content found in source documents rather than the skills categories being pre-determined by the researchers or based on existing taxonomies. Each document was read by a team member and a list of skills was developed. To allow for comparison and the next coding step across documents, broad categories or buckets of skills were created. For example, the category of research workflows includes skills such as the ability of a curator to understand research practices, workflows, and/or the ability of the curator to understand disciplinary norms and standards. After categories were developed, the competency documents were then re-coded for each category. As competencies or skills were mentioned, the researchers recorded instances for each category.

\section{Suitability of Competencies as Data Points}

Speaking about management, Jordan and Lloyd (2017) argue that human resource planning in libraries calls for the careful selection and recruitment of staff. One way this is accomplished is to formalize positions by defining job responsibilities to make work predictable and regular. In the case of scholarly communication, the existence of a disciplinary consensus about the skills individuals ought to possess would suggest the presence of formalized roles brought about by restructuring. Organizations do not constitute professions; however, they do employ the individuals who comprise them. As noted earlier, organizational formalization is associated with a decreased rate of change, so if ARL libraries are creating scholarly communication positions, it is more likely that scholarly communication work will be sustainable in the future.

\section{FINDINGS}

\section{Number of Scholarly Communication Librarians in ARL Libraries}

The number of scholarly communication librarians has been steadily on the rise since 2012 when data was first collected, as is demonstrated in Figure 1. Between 2012 and 2016, scholarly communication positions with the job titles scholarly communication (SCHOLAR; i.e., focusing on open access, etc.) and digital curation (DIGICUR; i.e., focusing on research data management, etc.) increased annually in ARL libraries. As indicated previously, 2012 marked the first year that ARL collected data for these positions; in 2012 SCHOLAR data was combined with other codes given the low number of positions and is, therefore, not presented in Figure 1. Interestingly, as shown below, growth in digital curation positions totaled $27 \%$. Scholarly communication growth was far more rapid with an increase of $49 \%$. A conclusion to draw is that the number of scholarly communication librarians in ARL libraries has grown since data was first collected and that the total of the two combined (as of 2016) was roughly 225 individuals.

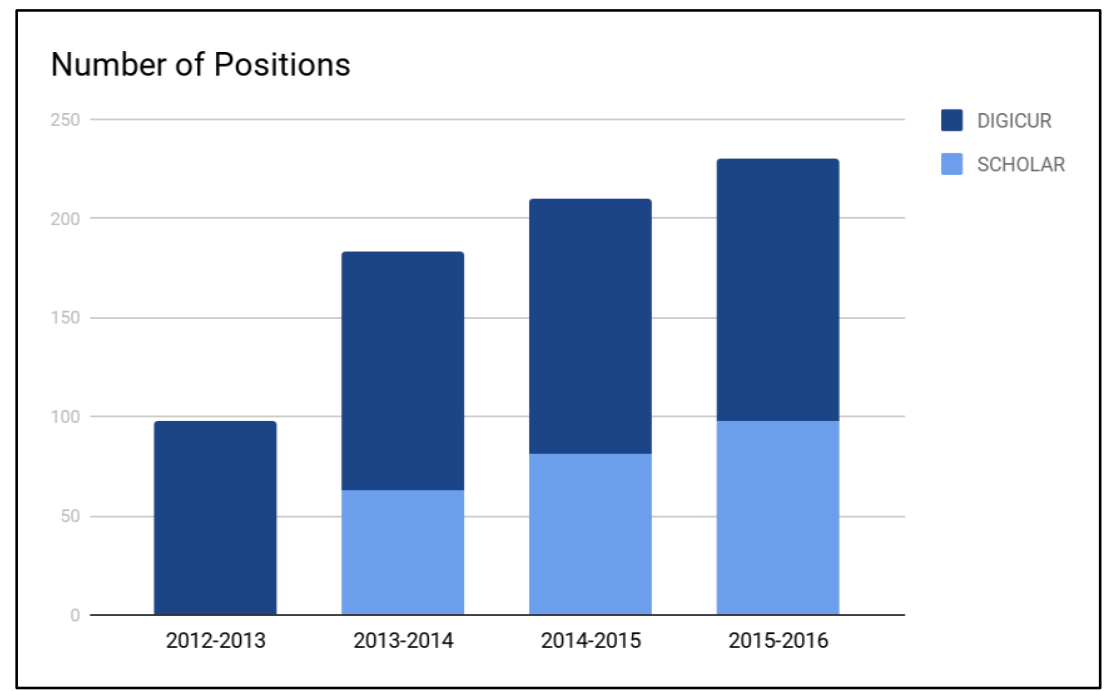

Figure 1. Scholarly communication (SCHOLAR) and digital curation (DIGICUR) positions at ARL libraries, 2012-2016.

\section{Identification of Competencies and Agreement Within Documents}

Coding of the competencies examined in this paper identified 23 categories for information professionals to perform digital curation and/or research data management work (see Table 1). Of these categories, twelve were found across all three competency publications. These 12 skills are: advocacy and outreach, instruction, data preservation, data management, data selection, 
data repository platforms, data linking, data audits, data type best practices, licensing data, data organization, and information discovery. An additional seven skills were found across two competency documents. These skills were: some type of discipline knowledge, data analysis skills, an understanding of funder requirements, knowledge of research workflows, data citation, data sharing, and data visualization skills. Finally, four skills were limited to only one competency document. These skills were: data security, programming and scripting, a background in science, technology, engineering, or medicine, and an understanding of publisher requirements.

\begin{tabular}{|c|c|c|c|}
\hline Competency or Skill & $\begin{array}{c}\text { Matrix of Digital } \\
\text { Curation Knowledge } \\
\text { (2009) }\end{array}$ & $\begin{array}{c}\text { Preparing the } \\
\text { Workforce for Digital } \\
\text { Curation (2015) }\end{array}$ & $\begin{array}{c}\text { Librarians' Competencies } \\
\text { Profile for Research Data } \\
\text { Management (2016) }\end{array}$ \\
\hline Advocacy \& Outreach & 1 & 1 & 1 \\
\hline Data Audit & 1 & 1 & 1 \\
\hline Data Linking & 1 & 1 & 1 \\
\hline Data Management & 1 & 1 & 1 \\
\hline Data Organization & 1 & 1 & 1 \\
\hline Data Preservation & 1 & 1 & 1 \\
\hline Data Repository Platform & 1 & 1 & 1 \\
\hline Data Selection & 1 & 1 & 1 \\
\hline Data Types & 1 & 1 & 1 \\
\hline Information Discovery & 1 & 1 & 1 \\
\hline Instruction & 1 & 1 & 1 \\
\hline Licensing Data & 1 & 1 & 1 \\
\hline Discipline Knowledge & 0 & 1 & 1 \\
\hline Data Analysis & 0 & 1 & 1 \\
\hline Funder Requirements & 0 & 1 & 1 \\
\hline Research Workflows & 0 & 1 & 0 \\
\hline Data Citation & 0 & 1 & 0 \\
\hline Data Sharing & 0 & 1 & 0 \\
\hline Data Visualization & 1 & 1 & 0 \\
\hline Data Security & 0 & 1 & 1 \\
\hline Programming \& Scripting & 0 & 1 & \\
\hline Education in STEM & 0 & 0 & \\
\hline Publisher Requirements & 0 & 1 & \\
\hline Tab & 1 & 1 & \\
\hline Skils & 1 & 1 & \\
\hline
\end{tabular}

Table 1: Skills required for digital curation per the selected guidelines documents.

As noted above, competencies documents possessed a high degree of agreement expressed in skill categories. Such agreement is notable, because all three documents were written by separate groups over the past decade with notable disciplinary qualifications. Regarding agreement among documents, the most similar were the Librarians' Competencies Profile for Research Data Management and Preparing the Workforce for Digital Curation with over $78 \%$ agreement (18 of 23 skills). The Matrix of Digital Curation and the Preparing the Workforce for Digital Curation documents had the next closest agreement with 61\% or 14 out of 23 points of overlap.

\section{DISCUSSION}

To address the question of sustainability, we consider our findings overall. Based on gathered ARL data, scholarly communication information professionals, especially generalists with the title Scholarly Communication Librarian, emerged in academic libraries in force through the 2010s. The upward trend in the growth of this position leads us to believe that this aspect of the information professions is in demand and that the work being done is both necessary and appreciated. Consensus in competencies suggests that the information professions are in agreement about what ought to be done in support of researchers as they seek assistance with digital curation and research data management. This implies that the role of the scholarly communication information professional, at least in terms of his/her work, is becoming formalized. We take the formalization of digital curation work to be an indicator of the maturation of the field as it coalesces around established competencies.

Based on reviewed literature and study findings, the time between 2009 and 2015 appears to have been pivotal in the formation and coalescence of scholarly communication work by information professionals. In 2009, the ACRL Scholarly Communication Roadshow began educating librarians and other information professionals about scholarly communication writ large. By 2012, ARL had begun to collect data on positions with the title Scholarly Communication Librarian, but did not find they had enough data to warrant reporting it separately from other positions. A divergence in data collection classifications was allowed to form 
between Scholarly Communication and Digital Curation, despite overlap in the work carried out. In 2012, respondents to the COPPUL survey supplied data indicating scholarly communication as an area of specialization had not coalesced (Swanepoel, 2015). Yet, by 2013, ARL was collecting data about scholarly communication librarians with over 50 positions in the 125 ARL libraries. In 2015 and 2016, two separate documents were published that indicated 78\% agreement in terms of the required skills and competencies for the sub-area of digital curation (Librarians' Competencies Profile, 2016; Preparing the Workforce, 2015). By 2017, the ACRL Roadshow organizers found the knowledge of audience members had improved to the point where it was necessary reconfigure their curriculum (Cross, Oleen, \& Perry, 2017), implying that a level of formalization had occurred in the information professions and information agencies. Based on these findings, the answer to research question two (RQ2) is digital curation has emerged as a cohesive sub-area of practice.

Further evidence for the emerging cohesiveness of practice in the sub-area of digital curation (and research data management) comes from findings associated with the three competencies documents that we examined. These documents were published at extreme ends of what the literature points to as a formative period for the field of scholarly communication within information agencies; they were also published before and after the establishment of the area as a formal title by ARL. The Matrix of Digital Curation Knowledge (2009) is the most different of the three competencies documents studied, implying that since its publication the sub-area of digital curation has coalesced. The competencies identified in 2015 (Preparing the Workforce for Digital Curation) and 2016 (Librarians' Competencies Profile for Research Data Management) demonstrate a mature understanding of this area of scholarly communication information work. All but one of the competencies in the 2009 document are included in later documents. Further, 6 of the 23 competencies shared by the 2015 and 2016 documents are unique to newer publications, having been identified and added since 2009. We interpret this as evidence of the maturation of this sub-area of practice within ARL information agencies and as a de facto formalization of associated work.

\section{DOI and the Future of Scholarly Communication Information Professionals}

Based on these findings and the concepts of restructuring and formalization from DOI and organizational innovation literature, we predict that increased formalization within information agencies will contribute to a slowing of change for scholarly communication information professionals. Therefore, to answer research question one (RQ1), we predict scholarly communications work will remain sustainable in the future. Staff are being brought in to do work in ARL libraries, and that work increasingly, at least in digital curation/research data management, is consistently codified in terms of the competencies and skills that practitioners require. Work in areas of scholarly communication has been made increasingly predictable and regular, in support of human resource planning (Jordan \& Lloyd, 2017) as demonstrated in the consensus about professional skills and competencies. Presumably, these positions have diffused, and are diffusing, through the information professions, as implied by the success of the ACRL Roadshow. The coherence of competencies documents and the number of positions within ARL information agencies also suggests that most ARL information agencies are in, or have moved beyond, the restructuring stage of Rogers' (2003) innovation-decision process.

\section{Study Limitations and Future Work}

The future of ARL information agencies providing scholarly communication support to scholars appears to be sustainable, but there are limitations to this study. The data we collected only allowed us to examine two concepts from DOI and organizational innovation literature. Indicators such as ARL data and the cohesiveness of professional competencies documents suggest that scholarly communication work has entered the late stages of Rogers' innovation-decision process, but we did not look at individual adoption-decisions inside agencies.

Speaking about the process by which organizations "choose" to adopt or reject an innovation, Rogers notes how the process is not linear; at any point, steps in his model may be skipped, left unfinished, or started again later (p. 421). Without data to test Rogers' model, we do not know who made decisions to hire scholarly communication professionals in ARL information agencies, if positions resembled those described in competencies documents, and if staff communicate with stakeholders to demonstrate the value that they provide. The creation of new positions hints that scholarly communication work is sustainable, in that it has been formalized, but limitations associated with our data mean the long-term is uncertain. To address uncertainty, future research should examine how scholarly communications positions are created and evaluate their value, which may shape the sustainability of the work that scholarly communication information professionals carry out. One way to gather data would be to interview decision-makers who are responsible for creating positions in ARL libraries as well as the scholars who use scholarly communication services.

Another limitation associated with this paper carries over to high-level traits that are associated with organizational innovation. In this paper, much as has been made of formalization as a predictive indicator, but we did not examine the work that is actually carried out within ARL libraries. Therefore, it is possible that positions were less formal than competencies documents suggest. 
Additionally, DOI and organizational innovation literature provide other variables that may shed light on if scholarly communication information services are likely to remain sustainable in the future.

Briefly discussed earlier, the variables we did not examine in this study include: centralization, complexity, interconnectedness, organizational slack, and size. As other ARL information agencies attempt to create positions, centralized decision-making by university administrators may intervene. A lack of available resources may also prevent positions from being filled. The financial state of many public universities is troubled, and today 46 U.S. states spend less per-student than a decade ago (Mitchell, Leachman \& Masterson, 2016). Organizational size also correlates with innovation, and as scholarly communication positions diffuse through the information professions, it is likely that small or medium-sized universities will not be able to provide the same level of support as their larger counterparts. Wilder (2017, p. 4) reports that in 2015 the typical ARL library employed 84 professional staff, which is much larger than libraries at liberal arts colleges and teaching universities. To account for influences such as these, future work should seek to collect data that provides a more holistic view of scholarly communication position stability. Additionally, because organizational size is a factor to consider, future work should look at information agencies other than ARL libraries, because these libraries tend to be very large.

\section{CONCLUSION}

Our findings revealed that the work of scholarly communication information professionals has formalized since 2009. Using two concepts from DOI and organization innovation literature, despite the limitations of this study, we infer that there is value in the work these professionals do, and conclude that the field is entering into a period of clarifying itself (using Rogers' (2003) terminology) that is indicative of its sustainability within ARL libraries. Given the coalescence of practice in the sub-area of digital curation, scholarly communication will likely continue to remain a sustainable area of practice in the information professions. However, more work remains to be done. The data collected in this study was insufficient to test other concepts from DOI, which leads us to conclude that, while the present is stable, the long-term is much less predictable. Future research should seek to move beyond this effort and examine the emergence of scholarly communications work within specific organizations, the value that this work delivers to researchers, and its potential to create a reliable, long-term growth opportunity for all types of information agencies.

\section{ACKNOWLEDGMENTS}

The authors would like to thank ARL for providing access to its data.

\section{REFERENCES}

Brantley, S., Bruns, T. A., \& Duffin, K. I. (2017). Librarians in transition: Scholarly communication support as a developing core competency. Journal of Electronic Resources Librarianship, 29(3), 137-150. doi:10.1080/1941126X.2017.1340718

Brundtland, G. H. (1987). Report of the World Commission on environment and development: Our common future. United Nations.

Borgman, C. L. (1990). Scholarly communication and bibliometrics. Newbury Park: Sage Publications.

Borgman, C. L. (2000). Digital libraries and the continuum of scholarly communication. Journal of Documentation, 56(4), 412-430.

Bossaller, J. S., \& Moulaison Sandy, H. (2017). Documenting the conversation: A systematic review of library discovery layers. College \& Research Libraries, 78(5), 602-619. doi:10.5860/crl.78.5.602

Calarco, P., Shearer, K., Schmidt, B., \& Tate, D. (2016). Librarians' competencies profile for scholarly communication and open access. Retrieved from Confederation of Open Access Repositories website: https://www.coar-repositories.org/files/Competencies-for-ScholCommand-OA_June-2016.pdf

Chen, S. T., \& Chang, B. G. (2012). The effects of absorptive capacity and decision speed on organizational innovation: A study of organizational structure as an antecedent variable. Contemporary Management Research, 8(1), 27-50.

Cross, W., Oleen, J., \& Perry, A. (2017). Jump start your scholarly communication initiatives: Lessons learned from redesigning the scholarly communications roadshow for a new generation of librarians. In: At the Helm: Leading Transformation, the Proceedings of the ACRL 2017 Conference. 361-371. Chicago: Association of College and Research Libraries, a division of the American Library Association, 2017. Retrieved from http://www.ala.org/acrl/sites/ala.org.acrl/files/content/conferences/confsandpreconfs/2017/JumpStartYourScholarlyCommunicationInitiatives.pdf

Fearon, D., Gunia, B., Lake, S., Pralle, B. \& Sallans, A. (2013). Research in Data Management Services (SPEC KIT 334). Association of Research Libraries: Washington, D.C. Retrieved from: https://doi.org/10.29242/spec.334

Green, E. (2016, May 12). What are the most-cited publications in the social sciences (according to Google Scholar)? [blog post]. Retrieved from http://blogs.lse.ac.uk/impactofsocialsciences/2016/05/12/what-are-the-most-cited-publications-in-the-social-sciences-according-togoogle-scholar/

Hage, J., \& Aiken, M. (1967). Program change and organizational properties a comparative analysis. American Journal of Sociology, 72(5), 503-519. 
Hayes, C., \& Kelly, H. E. (2017). Who's talking about scholarly communication? An examination of gender and behavior on the SCHOLCOMM Listserv. Journal of Librarianship and Scholarly Communication. 5(1). doi:10.7710/2162-3309.2017

Hey, T, Tansley, S., \& Tolle, K. (2009). The fourth paradigm: Data-intensive scientific discovery. Redmond, Washington: Microsoft Research.

Howard, H. A. (1981). Organizational structure and innovation in academic libraries. College \& Research Libraries, 42(5): 425-34.

Ketchum, A. M. (2017). The research life cycle and the health sciences librarian: Responding to change in scholarly communication. Journal of the Medical Library Association, 105(1), 80-83. doi:10.5195/jmla.2017.110

Klain-Gabbay, L. \& Shohamb, S. (2016). Scholarly communication and academic librarians. Library \& Information Science Research, 28(2), 170-179.

Kowalski, M. (2017). Breaking down silo walls: Successful collaboration across library departments. Library Leadership \& Management, $31(2), 1-15$.

Kyrillidou, M, \& Morris, S., eds. (2013). ARL Annual Salary Survey 2012-2013. Washington, DC: Association of Research Libraries. Retrieved from https://doi.org/10.29242/salary.2012-2013

Kyrillidou, M, \& Morris, S., eds. (2014). ARL Annual Salary Survey 2013-2014. Washington, DC: Association of Research Libraries. Retrieved from https://doi.org/10.29242/salary.2013-2014.

Kyrillidou, M, \& Morris, S., eds. (2015). ARL Annual Salary Survey 2014-2015. Washington, DC: Association of Research Libraries. Retrieved from https://doi.org/10.29242/salary.2014-2015

Lee, C. (2009). Matrix of digital curation knowledge and competencies. Retrieved from https://ils.unc.edu/digccurr/digccurr-matrix.html

Lewis, R., Sarli, C., \& Suiter, A. (2015). Scholarly output assessment activities (SPEC Kit 346). Association of Research Libraries, Washington, D.C. Retrieved from https://doi.org/10.29242/spec.346

Maron, N. L. \& Smith, K. K. (2009). Current models of digital scholarly communication: Results of an investigation conducted by Ithaka for the Association of Research Libraries. The Journal of Electronic Publishing, 12(1). doi:10.3998/3336451.0012.105

Mitchell, M., Leachman. M., \& Maserson, K. (2016). Funding down, tuition up state cuts to higher education threaten quality and affordability at public colleges. Washington, D.C.: Center on Budget and Policy Priorities. Retrieved from https://www.cbpp.org/sites/default/files/atoms/files/5-19-16sfp.pdf

Montana, P. J., \& Charnov, B. H. (1993). Management. Hauppauge, N.Y: Barron's.

Morris, S. (2017). ARL Annual Salary Survey 2015-2016. Washington, DC: Association of Research Libraries. Retrieved from https://doi.org/10.29242/salary.2015-2016

National Research Council. (2015). Preparing the workforce for digital curation. Washington, DC: The National Academies Press. https://doi.org/10.17226/18590

Novak, J., \& Day, A. (2015). The libraries they are a-changin': How libraries reorganize. College \& Undergraduate Libraries, 22(3-4), 358373. doi: 10.1080/10691316.2015.1067663

Oxford. (n.d.). Organization. Retrieved from https://en.oxforddictionaries.com/definition/us/organization

Potvin, S. (2013). The principle and the pragmatist: On conflict and coalescence for librarian engagement with open access initiatives. The Journal of Academic Librarianship, 39(1), 67-75.

Pugh, D. S. (1990). Organization theory: Selected readings. Harmondsworth: Penguin.

Regazzi, J. J. (2015). Scholarly communications: A history from content as king to content as kingmaker. New York: Rowman \& Littlefield.

Rodriguez, J. E. (2015). Scholarly communications competencies: open access training for librarians. New Library World, 116(7/8), 397-405. doi:10.1108/NLW-12-2014-0140

Rogers, E. M. (1962). Diffusion of innovations. New York: Free Press of Glencoe.

Rogers, E. M. (2003). Diffusion of innovations (5th ed.). New York: Free Press.

Ryan, B., \& Gross, N. C. (1943). The diffusion of hybrid seed corn in two Iowa communities. Rural Sociology, 8(1), 15-24.

Swanepoel, M., Kehoe, I., Hohner, M., Shepstone, C., Vanderjagt, L., Wakaruk, A., [...] Winter, C. (2015). Developing a community of practice: Report on a survey to determine the scholarly communication landscape in western Canada. Unpublished manuscript. http://hdl.handle.net/10133/4784b

Valente, T. W., \& Rogers, E. M. (1995). The Origins and Development of the Diffusion of Innovations Paradigm as an Example of Scientific Growth. Science Communication, 16(3), 242-273. http://doi.org/10.1177/1075547095016003002

Wilder, S. (2017). Hiring and staffing trends in ARL libraries. Retrieved from http://www.arl.org/storage/documents/publications/rli-2017stanley-wilder-article2.pdf

$81^{\text {st }}$ Annual Meeting of the Association for Information Science \& Technology | Vancouver, Canada | 10 - 14 November 2018 Author(s) Retain Copyright 